\title{
An interactive approach for solar energy system: design and manufacturing
}

\author{
Benbaziz Djallal Eddine Mahdi ${ }^{1}$, Hassini Abdelatif ${ }^{2}$, Mohammed Amine Zafrane ${ }^{3}$ \\ ${ }^{1,2}$ University of Oran 2 Mohamed ben Ahmed, Institute of Maintenance and Industrial Safty Oran, Algeria \\ ${ }^{3}$ Department of Electronic, University of Science and Technology of Oran Mohamed Boudiaf, Algeria
}

\begin{tabular}{|c|c|}
\hline Article Info & ABSTRACT \\
\hline Article history: & The energy production in the word is a very complex problem with decreasing \\
\hline Received Jul 7, 2019 & focuses on the development and the optimization of parabolic concentrator \\
\hline Revised Feb 26, 2020 & using an interactivity approach and virtual design tools. Recently, several \\
\hline Accepted Mar 21, 2020 & $\begin{array}{l}\text { works have been developed in this area. In this study, a new conception, design } \\
\text { Optimization approach has been involved in system energy design including }\end{array}$ \\
\hline Keywords: & $\begin{array}{l}\text { new concept. The design strategy has been successfully applied to design } \\
\text { problems. The optimizer tool developed for based on Heuristic: Gravitational }\end{array}$ \\
\hline $\begin{array}{l}\text { Gravitational search algorithm } \\
\text { interactive approach } \\
\text { Prototype } \\
\text { Solar energy }\end{array}$ & $\begin{array}{l}\text { Search Algorithm. The results of the presented in this paper are significant in } \\
\text { the system energy design, which presents an effective approach of development } \\
\text { by reducing the cost of installation, the time of analysis by increasing } \\
\text { the radiation and solar flux concentrated within the parabola generating an } \\
\text { increase in accumulated energy. }\end{array}$ \\
\hline
\end{tabular}

Copyright ()$^{2} 2020$ Institute of Advanced Engineering and Science. All rights reserved.

\section{Corresponding Author:}

Benbaziz Djallal Eddine Mahdi,

Institute of Maintenance and Industrial Safty Department of Electromechanical,

University of Oran 2 Mohamed Ben Ahmed,

BP 05 Route de l'Aeroport, Es-Senia Oran 31024, Algeria.

Email: benbaziz.mahdi@univ-oran2.dz

\section{INTRODUCTION}

In recent decades, given the increase in energy needs, a reorientation towards renewable energies is necessary, by providing a sustainable and significant energy potential, the development of structures adequate to this need becomes essential for almost all countries [1]. This allows an economic increase by creating projects and jobs [2]. Solar is the most used given its low cost and its simplicity of use, the earth receives daily a significant rate of energy coming from the sun in the form of radiation subjected to several criteria such as the weather and the atmosphere. However, Algeria presents the most significant renewable energy potential ranks at the top of the African and Mediterranean countries. This energy potential linked to several types of sources, nevertheless solar energy remains the most important in availability, power and probably also the most competitive to develop in the future in several forms.Algeria is one of the largest solar deposits in the world with annual hours of sunshine which can vary from about 2000 to 3900 , and a daily irradiation of 3.000 to $6.000 \mathrm{Wh} / \mathrm{m} 2$ equivalents to 10 times the global consumption. Figure 1 shows the differentrenewable energy sources operations in Algeria. However, a high thermal comfort levels is achived in the South.

In addition to wind and photovoltaic energies, solar thermal or concentration module can bring a big plus in the field of renewable energies and will be of great help in the supply of energy useful for the production of electricity [3]. The conversion of energy to thermal requires a receiver with a parabolic cavity [4]. Four concentration technologies are located: semi-parabolic collectors, linear Fresnel reflectors, central receiver systems (power towers) and parabolic concentrators [5]. This research interests in methods of the development (Parabolic concentrator) analysis and in attendance of the new design to perform the process 
of conception on a parabolic configuration; two contributions are covered. First, a new model of the conception's problem has been developed based on a sketch Up which is an interactive 3D modeling software, and a demonstrative class dispatcher of free-hand drawn sketches [6] in order to improve the regard of the interactivity system (solar irradiation and Parabolic concentrator), based on an efficient algorithm: Gravitational Search Algorithm, this latter have been proposed in order to take into account the non-linear constraints, the Virtual Reality manufacturing tool has been developed. Then a development, test and manufacturing of an electronic board for parabolic concentrator, aimed to ensure the feasibility and the robustness of the optimal solution obtained and the optimal solar track. Finally a build of a law coasted prototype with modern materials [7,8], testing and design refinement, this process is established with a various engineering phases schematized in Figure 2.

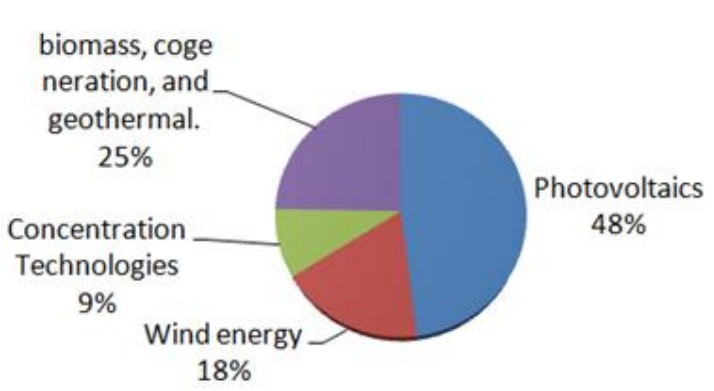

(a)

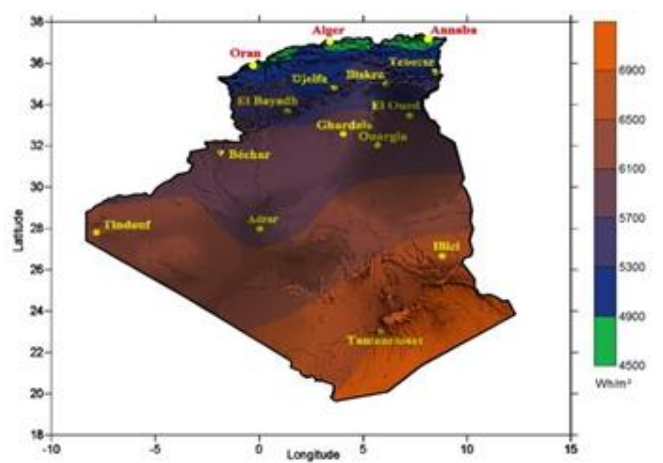

(b)

Figure 1. (a) The distribution of renewable energy operation and (b) the layout of lime points in Algeria

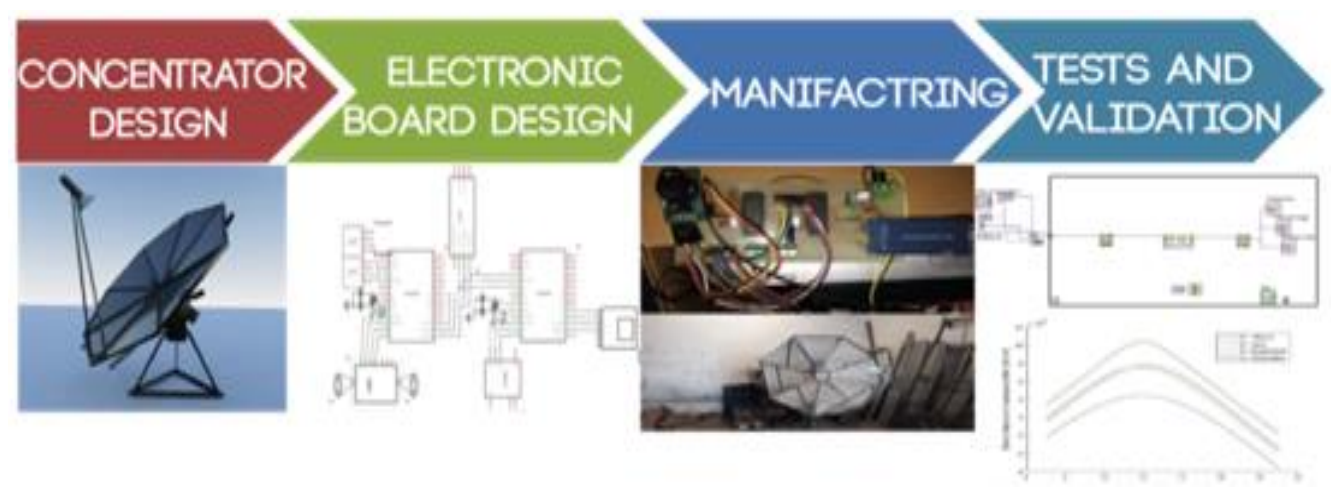

Figure 2. Simulation processes manufactory

\section{OVERVIEW OF THE SOLUTION OPTIONS}

However, given the bet to contribute to stopping ecological degradation, and to remedy the significant drop in fossil fuel sources, many studies focus on renewable energies, because these have the potential to provide an unlimited, clean and sustainable energy [9], and economically minimize costs, and help create jobs. Solar and wind energy are unanimous in the field of renewable energies. The mix of these two opposite forms is able to provide the energy we need throughout the year and can to some extent follow the seasonal load curve [10]. Several methods and technologies allow us to use the more important of these two forms, which is solar energy. Mainly: photovoltaics and solar thermal, in addition the concentration of solar thermal energy contributes significantly to the supply of electricity, and represent an interactive and growing field. Among these methods we quote: the semi-parabolic collector, the linear reflectors Fresnel, central reception systems (power towers), and parabolic collectors [11]. In this regard, we have proposed a practical contribution based on a parabolic configuration design and a powerful algorithm for design optimization. There are however, to save the different settings for each of the options are important. Therefore, a number of different detection systems are capable of detecting and mapping these variations. In addition, an advanced unit is developed with an altitude capability, when several sensors are connected simultaneously. In the Software section, a programming code is generated to simulate variations in radiation 
and solar flux. The aspects of real-time data acquisition were taken into account in this study. The goal is to design and manufacture an optimized parabola based on the results of the GSA algorithm, this prototype is lined with a glass or polished metal mirror used as reflector, which serves for maximum collection of solar radiation while throughout the day, a bi-axial tracking system is designed for this purpose [12].

\section{RESEARCH METHODOLGY}

\subsection{Virtual reality design}

The design of systems in mechanical engineering such as geared motors, parabolic concentrators is a very complicated operation that requires highly interactive software tools so it is important to diversify this interactive simulation to reach solar systems designers, and this makes it possible to understand the real aspect of the system. In order to have optimal results the use of virtual reality is a crucial asset. It defined as the use of computer systems to support several approaches in design like creation, modification, analysis, and optimization [13-15], the implemented process is the result of interactivity between the CAD namely (SolidWorks, Matlab, and LabView).

\subsection{Proposed mathematic model}

The mathematical model used in this research based on of Perrin Brichambaut [16] model, which takes into consideration certain number of physical phenomena such as thermal losses, optical yields [17]. The main objectives is the evaluation of the performance of solar energy conversion systems. A numerical simulation developed in this area to perform the irradiance and the solar flux, the model is described using the following equation. The solar flux is calculated by:

$$
Q=F_{r} \times\left(\eta \times D N I \times A_{a}\right)+\left(U_{l} \times A_{r} \times\left(T_{i}-T_{a m b}\right)\right.
$$

With $F_{r}$ is the heat dissipation factor calculated by:

$$
F_{r}=\frac{m \times C_{p}}{A_{a} \times U_{l}} \times\left(1-e^{\frac{A_{a} \times U_{l} \times F^{\prime}}{m \times C_{p}}}\right)
$$

$\boldsymbol{\eta}$ is optical efficiency which is given by:

$$
\eta=\tau \times \alpha \times \rho_{p}
$$

DNI is the solar irradiation which is given by:

$$
D N I=1367 \times h \times(1+0.03344 \times \cos (0.98 \times N)-2.8))
$$

We can express the height of the sun by:

$$
h=\arcsin (\sin (\rho) \times \sin (\theta)+\cos (\rho) \times \cos (\theta) \times \cos (\Omega))
$$

$\theta$ is the solar declination which is given by:

$$
\theta=\arcsin \left(0.398 \times \sin \left(\frac{360}{365 \times(N-82)+2 \times \sin \frac{360}{365 \times(N-2)}}\right)\right.
$$

And $\Omega$ is the hour angle that can be calculated with:

$$
\Omega=15 \times(T S V-12)
$$

TSV is the true solar time given by:

$$
T S V=T L+\frac{E_{t}+4 \times \lambda}{60-D E}
$$

and $E_{t}$ is the correction of the equation of time given by:

$$
E_{t}=9.87 \times \sin \left(2 \times N^{\prime}\right)-7.53 \times \cos N^{\prime}-\sin N^{\prime}
$$


With N' given by:

$$
N^{\prime}=\frac{360 \times(N-81)}{365}
$$

$A_{a}$ is The opening surface of the collector given by:

$$
A_{a}=\frac{\pi \times d^{2}}{4}
$$

$A_{r}$ is the surface of the receiver calculated by:

$$
A_{r}=2 \pi \times D_{o} \times h_{a}
$$

$\mathrm{U}_{1}$ is the thermal loss coefficient, we can calculate it with:

$$
U_{l}=\frac{1}{\frac{A_{r}}{\left(h_{w}+h_{r c a}\right) \times\left(\frac{1}{h_{r r a}}\right)}}
$$

$A_{C}$ The surface of the mirrors given by:

$$
A_{c}=2 \pi \times D_{v o} \times h_{p}
$$

$h_{w}$ is the coefficient of convection exchange between the glass and the atmosphere given by:

$$
h_{w}=\frac{0.3 \times R_{e}^{0.6} \times K}{D_{v o}}
$$

With $\mathrm{h}_{\text {rca }}$ is the radiative exchange coefficient between the glass and the atmosphere given by:

$$
h_{r c a}=\varepsilon_{v} \times \sigma \times\left(T_{v}+T_{a m b}\right) \times\left(T_{v}^{2}+T_{a m b}^{2}\right)
$$

$\mathrm{h}_{\text {rra is }}$ the radiative exchange coefficient between the absorber and the glass which is given by:

$$
h_{r r a}=\frac{\sigma \times\left(T_{v}+T_{r}\right) \times\left(T_{v}^{2}+T_{r}^{2}\right)}{\left(\frac{1}{\varepsilon_{r}}+\frac{A_{a}}{A_{c}}\right) \times\left(\frac{1}{\varepsilon_{v}}-1\right)}
$$

$F^{\prime}$ is the efficiency factor of the mirror given by:

$$
F^{\prime}=\frac{1}{\frac{U_{l}}{U_{l}}+\frac{D_{o}}{h_{f} \times D_{i}}+\frac{D_{o}}{2 K \times \ln \left(\frac{D_{o}}{D_{i}}\right)}}
$$

\subsection{Gravitational search algorithm (GSA)}

GSA [18] is a powerful meta-heuristic algorithm based mainly on the law of Newtonian gravity and motion [19-22], principally the influence of gravity leads to a movement of attraction between agents. In GSA, each mass has four characteristics: inertial mass, active gravitational mass, passive gravitational mass, [23]. The performance index of each agent is measured by its mass [24], in another way the heaviest agents match to the good convergence solution of the problem [25], due to the gravity forces, agents with the heavier masses will drive all agents to move towards it.

The position of an agent (object) is:

$$
X_{i}=X_{i}^{1}, X_{i}^{2}, \ldots \ldots, X_{i}^{n}
$$

The mass value of each object is determined according to its fitness value:

$$
M_{i}=\frac{f i t_{i}(t)-\operatorname{worst}(t)}{\sum_{j=1}^{N} f i t_{i}(t)-\operatorname{worst}(t)}
$$


By the calculating the mass of objects, they can interact by each other by:

$$
F_{i}^{d}(t)=\sum_{j \neq i r_{j}} G(t) \frac{M_{i}(t) \times M_{j}(t)}{R_{i j}(t)+r}\left(x_{j}^{d}(t)-x_{i}^{d}(t)\right)
$$

The acceleration of the agent is calculated by the second law of motion:

$$
a_{i}^{d}(t)=\frac{F_{i}^{d}(t)}{M_{i}(t)}
$$

Afterward, (23) and (24) are used to update the position of each agent. According to (23), the next velocity of the agent is calculated as a fraction of its current velocity added to its acceleration.

$$
\begin{aligned}
& v_{i}^{d}(t+1)=r_{i} \times v_{i}^{d}(t)+a_{i}^{d}(t) \\
& x_{i}^{d}(t+1)=x_{i}^{d}(t)+v_{i}^{d}(t+1)
\end{aligned}
$$

where $r_{i}$ and $r_{j}$ are two uniform distributed random numbers in the interval $[0,1]$. However, generating the pseudo code requires the following of several steps reported in the following Table 1 .

Table 1. Pseudo code

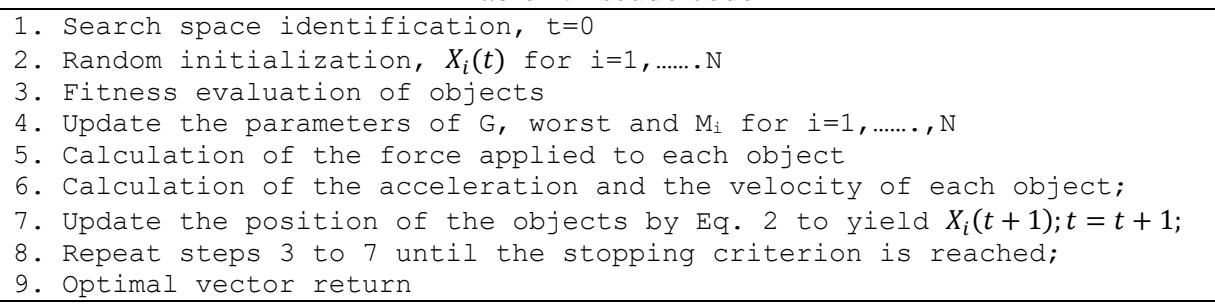

\subsection{Tracking system}

The challenge is to collect as much solar energy as possible using concentrator systems. Having found that energy production is affected by the following factors: the geographic location of solar radiation, the ambient temperature and weather in the region and the angle of incidence of the sun [26]. To this end, a system is designed to keep the surface of the sensor perpendicular to the sun $[27,28]$. The system in place makes it possible to follow the trajectory of the sun throughout the day in order to be able to capture the maximum of available energy. For this we distinguish two different methods: a passive one which does not require controllers, motors or gears. An active method that we recommend controlled by controllers, using motors and gears [29]. The principle of tracking is to reduce the angle formed by the sun's rays and the surface of the collector, in order to maximize the amount of energy captured. Thus a bi-axial tracking system has been designed and produced [30,31], provided with a dual axis tracking (azimuth and altitude) is more effective. In Figure 3, we provide our best estimates of the cost parameters of the tracking system.

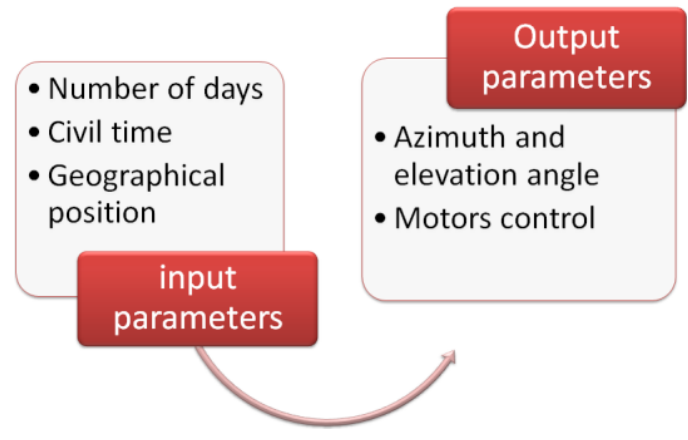

Figure 3. Tracking parameters 


\section{RESULTS AND DISCUSSIONS}

In this challenging economic and scientifics context, in fact, we have applied a novel methodology with height interactivity in the design of the system as described in Figure 4. In this regard, a powerfull interactive modeling design for solar stationbased on various CAD has been devoloped. A calculation and programming procedure is developed to simulate solar radiation in order to quantify it. In this respect, equations allow us to obtain an optimal concentration, giving a maximum flux by translating the position of the sun at each moment of the day. Figure 5 shows the change in direct radiation during the solstices of the four seasons (March 21, June 21, September 21 and December 21) from dawn to sunset.

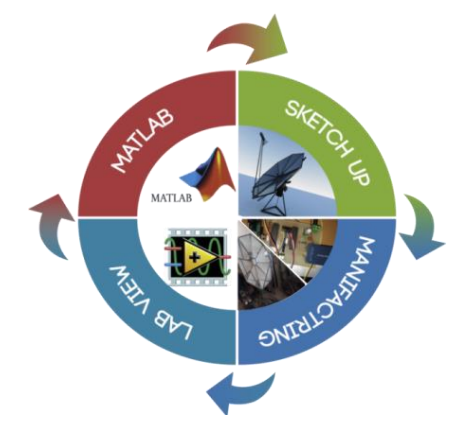

Figure 4. Interactive modeling tools

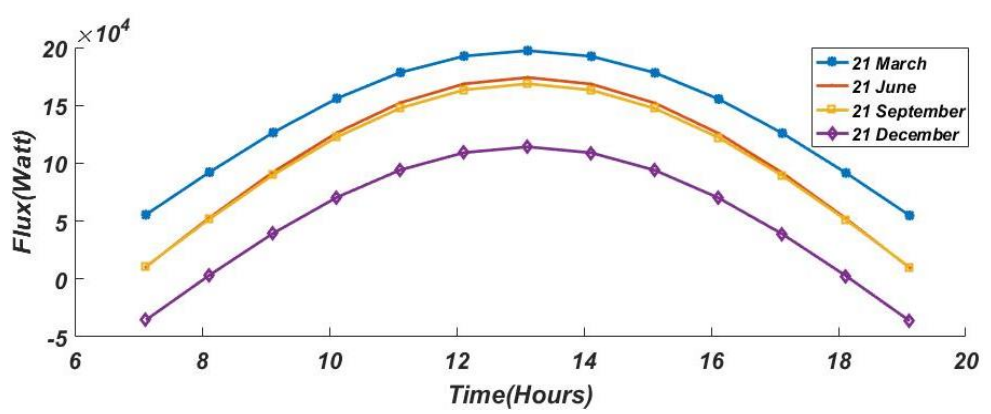

Figure 5. The evolution of the solar useful flux

The use of the gravitational search algorithm allows us to maximize the concentrated solar flux by optimizing geometrical and geographical parameters the following figures describe the evolution of solar flux during the day. Several control parameters are proposed in this paper in order to reach the best value, the following tables shows the parameters in question. As indicated in the Table 2, each simulation is runnig with different iteraction number. Moreover, Table 2 illustrate the parameters settings used in GSA algorihm that helps us to reach the best desird values. The results are random and do not depend on the number of iteration because we can have a result more meaningful with a less number of iteration, several tests allowed us to have the best results in a restrained range. We have noticed that the algorithm gives us approximately the same results on each control parameter.

In order to to design the parable in the best way several geometrical parameters has been optimized by executing three tests. Table 3 summarizes the obtained results for each parameter. From these results it was found that the best values are obtained at 400 iterations so we implemented these results in our program. As is shown in Figures 6 and 7, we translate the results of the flux obtained with the new parameters while comparing with that of the standard results.

Table 2. GSA parametrs setting

\begin{tabular}{lll}
\hline Case $1: 200$ Iterations & Case $2: 200$ Iterations & Case $3: 200$ Iterations \\
\hline N- masse $=800$ & N- masse $=800$ & N- masse $=800$ \\
Elitist Check: & Elitist Check: & Elitist Check: \\
Mass $\mathrm{Ma}=\mathrm{Mp}=\mathrm{Mi}=\mathrm{M}:$ Random & Mass $\mathrm{Ma}=\mathrm{Mp}=\mathrm{Mi}=\mathrm{M}:$ Random & Mass $\mathrm{Ma}=\mathrm{Mp}=\mathrm{Mi}=\mathrm{M}:$ Random \\
Velocity $:$ Random & Velocity $:$ Random & Velocity $:$ Random \\
\hline
\end{tabular}


Table 3. Benchmark results

\begin{tabular}{ccccccc}
\hline Parameters & Standard values & Minimum value & Maximum value & 200 Iterations & 400 Iterations & 800 Iterations \\
\hline $\mathrm{d}$ & 0.6 & 0.5 & 1 & 0.5 & 1 & 0.5 \\
$\mathrm{D}_{\mathrm{vo}}$ & 0.005 & 0.001 & 0.003 & 0.003 & 0.001 & 0.001 \\
$\mathrm{~h}_{\mathrm{p}}$ & 1.5 & 1 & 2 & 2 & 2 & 0.5 \\
$\mathrm{D}_{\mathrm{o}}$ & 0.05 & 0.005 & 0.2 & 0.05 & 0.05 & 0.05 \\
$\mathrm{~h}_{\mathrm{a}}$ & 0.3 & 0.1 & 0.5 & 0.1 & 0.1 & 0.1 \\
\hline
\end{tabular}

We noticed a significant increase of the solar flux which can be explained by which can be explained by the change in values of the diameter of the dish and also the height of the absorber (the flux is proportional to the diameter while the height of the absorber is disproportional to the flux). More results were proven, the implementation the Cartesian coordinates of our study area (the city of Oran) in order to have the best possible location for a maximum concentration of solar flux. Table 4 illustrates the optimal longitude and latitude parameters obtained in a defined interval. In addition, Figure 8 translates the obtained results.

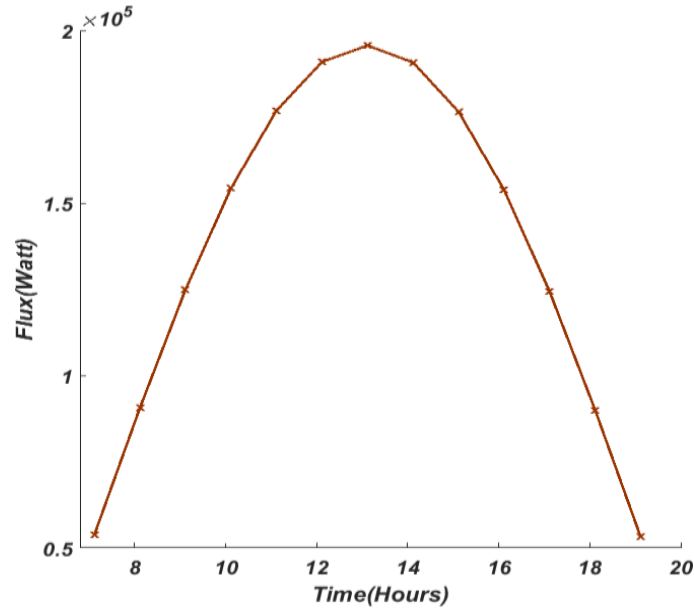

(a)

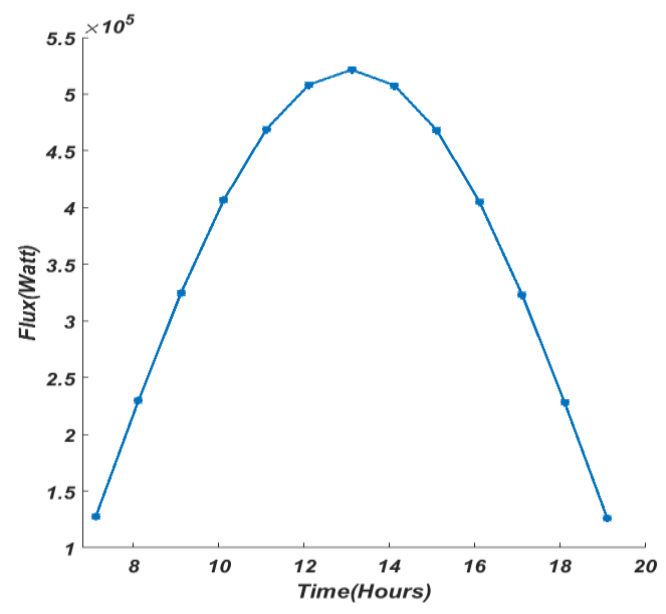

(b)

Figure 6. The evolution of solar useful flux in (a) standard settings and (b) optimal settings

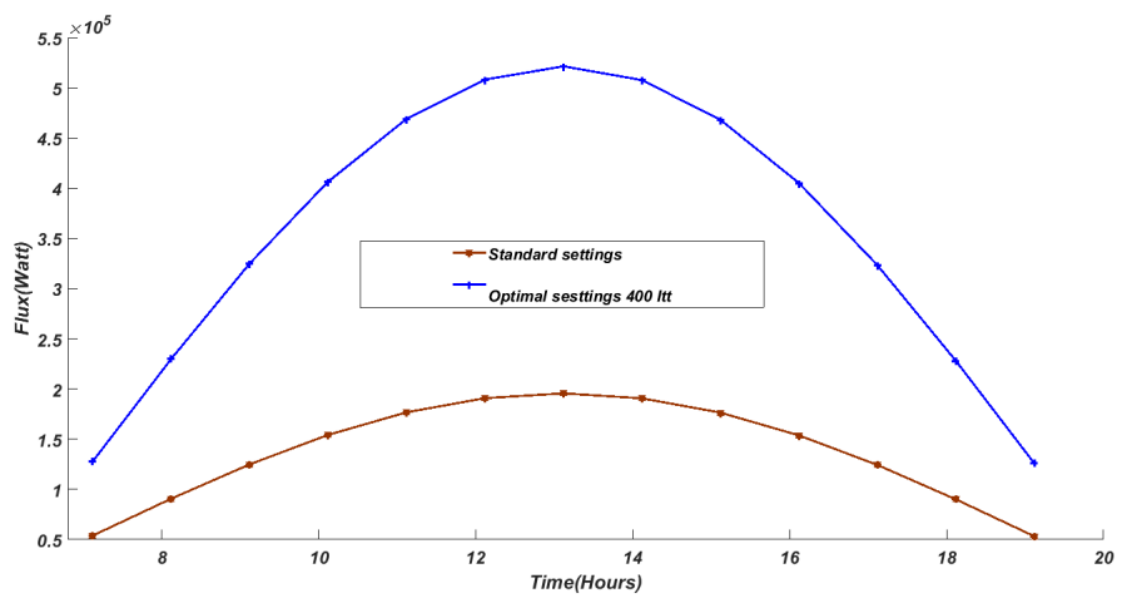

Figure 7. The comparison between the different parameters

Table 4. Benchmark results

\begin{tabular}{|c|c|c|c|c|}
\hline Parameters & Standard values & Minimum value & Maximum value & Optimal value \\
\hline $\boldsymbol{\rho}$ & $35.6911100^{\circ}$ & $35.372700^{\circ}$ & $35.70000^{\circ}$ & 35.6969 \\
\hline$\lambda$ & $-0.6416700^{\circ}$ & $-0.300000^{\circ}$ & $-0.70000^{\circ}$ & -0.3000 \\
\hline
\end{tabular}




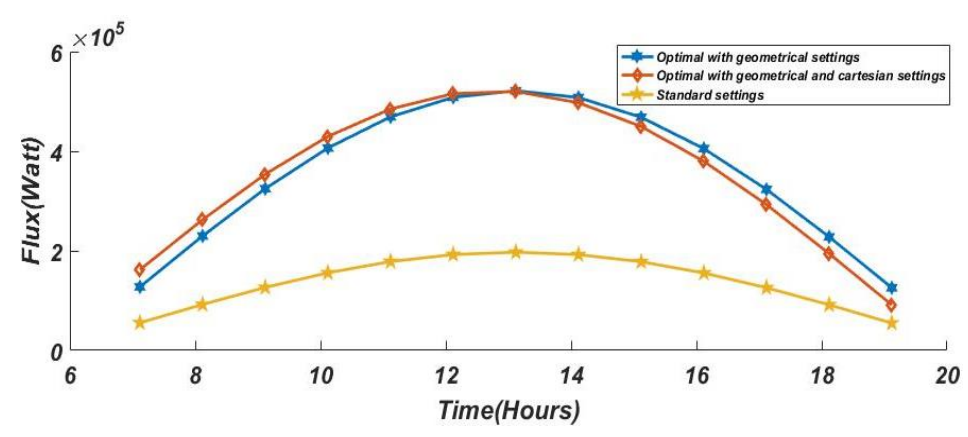

Figure 8. Comparison between the different settings

Moreover, the results obtained clearly show that the implementation of the Cartesian data can bring a plus to the phenomenon of concentration. It is noted that in the first half of the day (before solar noon) the solar flux is slightly higher while for the second period there is a slight decrease in solar flux. Despite this decrease, the results remain satisfactory because the largest solar flux rate is concentrated in the first period of the day.

\subsection{Experimental result: design and manufacturing}

In order to reduce costs by using modern inexpensive materials, the parabolic collector technology, which is still under development, is the best option in this regard. An interactive approach was taken to realize the concentrator at a lower cost and as simply as possible. First, we have established a design of the parable based on the software sketch Up. Figure 9 show us a simplified sketch of the concentrator.

Since this interactive design, we have realized the parable. The primary objective was to obtain satisfactory results with cheap and available materials in the market. For a better heat content the absorber is designed in cast iron, the base is in iron and the receiver is mirror glaces. Figure 10 shows the realized concentrator. For an optimal tracking of the sun, the implementation of a tracking system is necessary. This tracking is done quite independently, unlike parabolic cylindro-parabolic sensors. Figure 11 presents the regulation loop of the system.
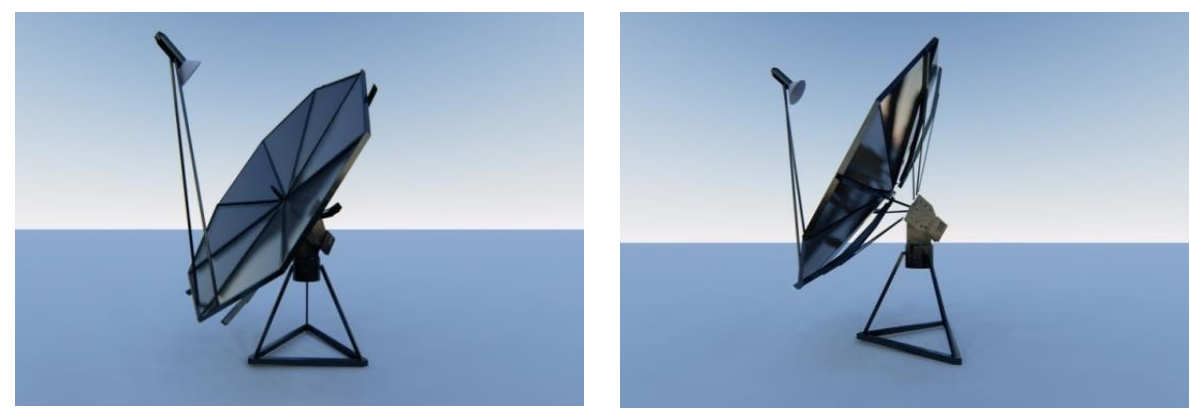

Figure 9. 3D view of design in sketch tool
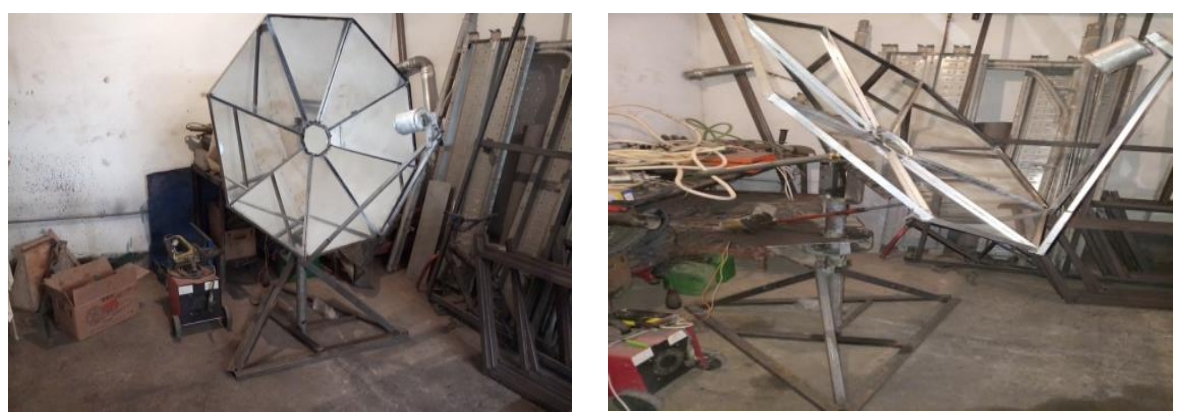

Figure 10. Manufacturing and assembly 


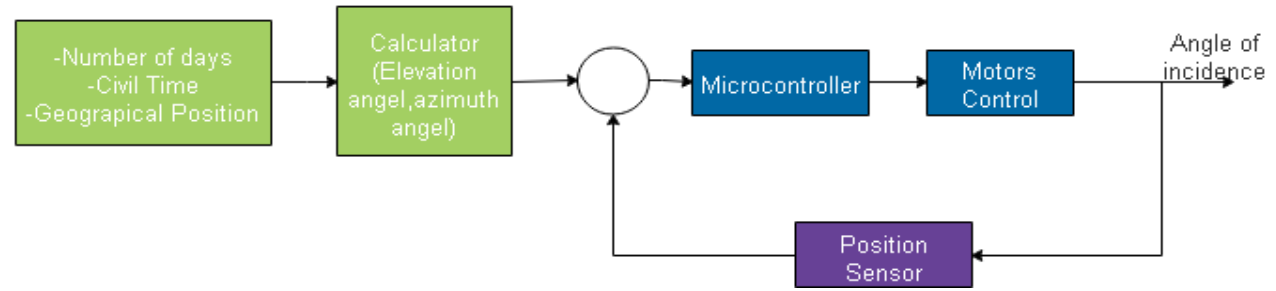

Figure 11. Block diagram of tracking system

An ATMEGA328 microcontroller which is easy to program via its card has been elected, it allows motor control and data acquisition, the motor-microcontroller link is possible thanks to FC03 accelerators, and synchronization is achieved by a clock Ds1302. Programming uses C language. The programming diagram followed is explained in Figure 12. The program developed here uses the value of the DNI to control the execution of instructions when it is started it calculates the elevation and azimuth angles, the translation of the pulses counted by the FC03 accelerators allows the control of the motors. Figure 13 describes the diagram of the assembled card. Which consists of two integrated Atmega board, the first is responsible for motor control and the other for storing the various information is related to the system. A SD memory card for storage and a LM74 sensor to measure the concentrator's temperature accompanies it. Moreover, to ensure the synchronization between the two circuits is attached by a DS1302 clock. Figure 14 shows the realized electronic board of the tracking system.

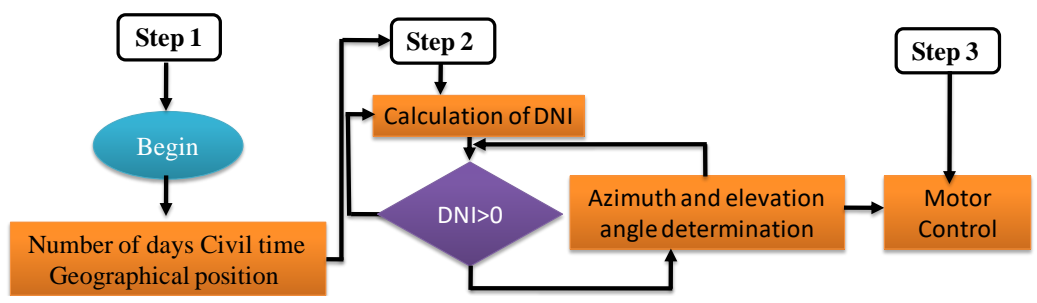

Figure 12. Programming flowchart

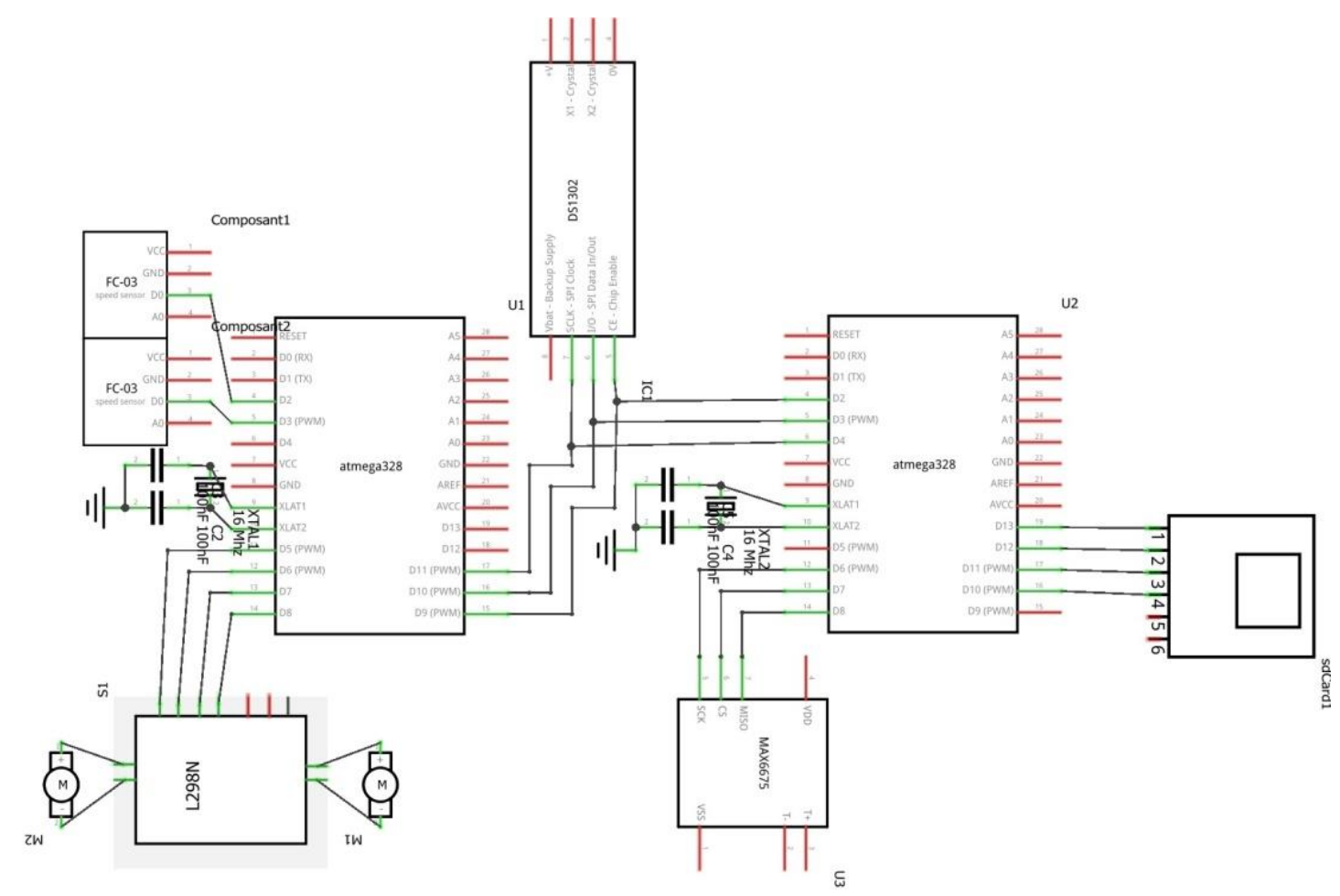

Figure 13. Descriptive diagram of the realized card 


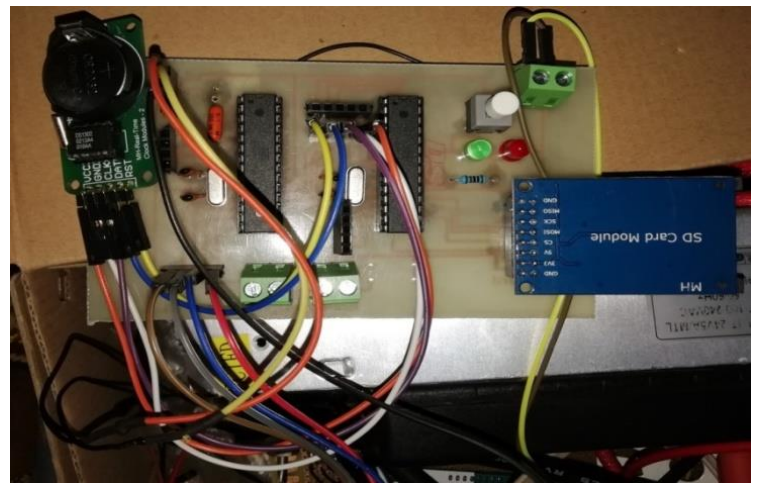

Figure 14. Tracking electronic card

From a practical point, the solar irradiance calculation approaches the theoretical calculation. It is done with the help of the temperature concentrated throughout the day. Figures 15 and 16 translate the obtained results from the calculations made throughout our study. They describe the evolution of experimental useful flux.

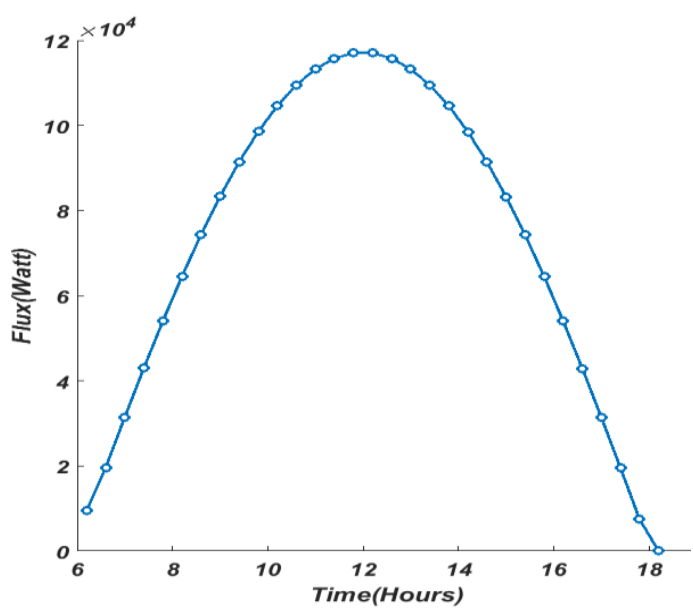

(a)

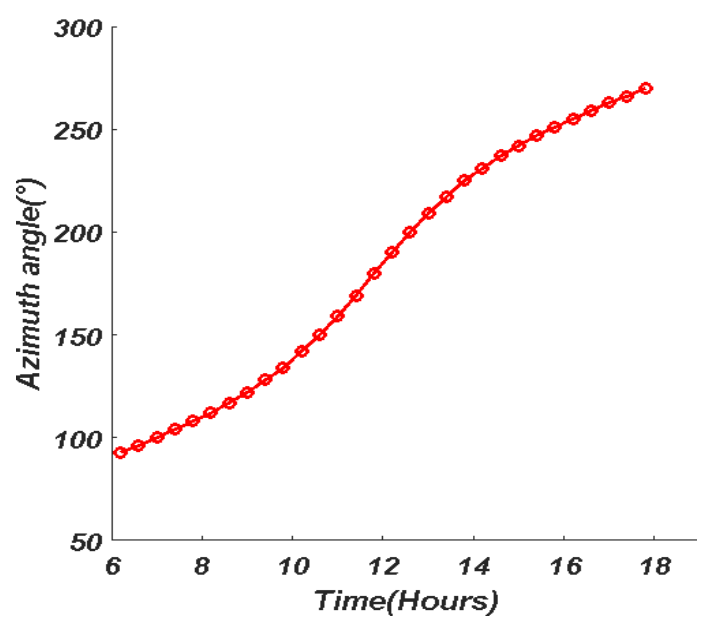

(b)

Figure 15. The evolution of (a) experimental useful flux and (b) solar useful flux in

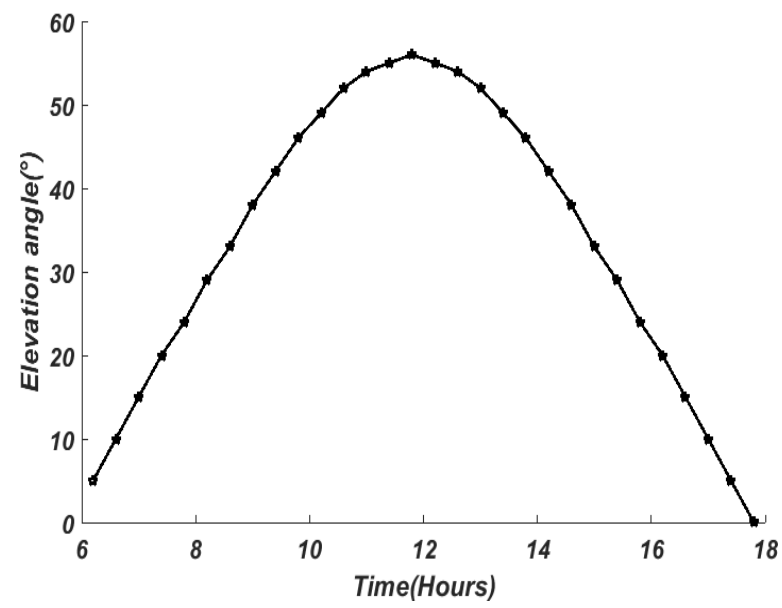

Figure 16. The evolution of the elevation angle 


\section{CONCLUSION}

The excellent results recorded by concentrator technologies in electrical and thermal production explains the reasons for its growing use, we see that these days the most important power plants in the world are using this technique. In this paper, we work for the implementation of a virtual manufacturing tool for solar station in our case a parabolic concentrator. Several CAD software has been used in our study (Matlab, LabView, Sketch Up, etc.). The followed approach has been demonstrated for renewable energies and has shown that interactive design optimization tools make a large contribution to the obtained result. The use of the optimization algorithm on the geometric parameters of the parabola and geography of the area shows excellent results in the concentrated flux compared with initial parameters. We noted that both of the diameter of the receiver and the height of absorber have a great influence on the obtained results.

\section{REFERENCES}

[1] J. P. Painuly, "Barriers to renewable energy penetration; a framework for analysis," Renewable energy, vol. 24, no. 1, pp. 73-89, 2001.

[2] M. Pehnt, "Dynamic life cycle assessment (lca) of renewable energy technologies," Renewable energy, vol. 31, no. 1, pp. 55-71, 2006.

[3] H. Müller-Steinhagen, "Concentrating solar thermal power," Phil. Trans. R. Soc. A, vol. 371, no. 1996, 2013.

[4] J. A.Harris and T. G. Lenz, "Thermal performance of solar concentrator/cavity receiver systems," Solar energy, vol. 34, pp. 2, pp. 135-142, 1985.

[5] A. El Ouederni, et al., "Experimental study of a parabolic solar concentrator," Revue des Energies Renouvelables, vol. 12 , no. 3, pp. 395-404, 2009.

[6] C. Collina, et al., "Sketch up: Towards qualitative shape data management," in Asian Conference on Computer Vision, 1998, pp. 338-345.

[7] S. Pavlovic, et al., "Experimental and numerical investigation on the optical and thermal performance of solar parabolic dish and corrugated spiral cavity receiver," Journal of cleaner production, vol. 150, pp. 75-92, 2017.

[8] A. Krothapalli and B. Greska, "Concentrated solar thermal power," Handbook of Climate Change Mitigation and Adaptation, pp. 1-27, 2014.

[9] M. Romero and A. Steinfeld, "Concentrating solar thermal power and thermochemical fuels," Energy \& Environmental Science, vol. 5, no. 11, pp. 9234-9245, 2012.

[10] D. Heide, et al., "Seasonal optimal mix of wind and solar power in a future, highly renewable Europe," Renewable Energy, vol. 35, no. 11, pp. 2483-2489, 2010.

[11] U. Pelay, et al., "Thermal energy storage systems for concentrated solar power plants," Renewable and Sustainable Energy Reviews, vol. 79, pp. 82-100, 2017.

[12] W. Nsengiyumva, et al., "Recent advancements and challenges in Solar Tracking Systems (STS): A review," Renewable and Sustainable Energy Reviews, vol. 81, pp. 250-279, 2018.

[13] M. M. M. Sarcar, K. M. Rao, and K. L. Narayan, "Computer aided design and manufacturing," PHI Learning Pvt. Ltd., 2008.

[14] M. A. Zafrane, A, Boudjemai, and N. Boughanmi, "Interactive design of space manufacturing systems, optimality and opportunity," International Journal on Interactive Design and Manufacturing (IJIDeM), vol. 13, no. 2, pp. 773-796, 2019.

[15] M. A. Zafrane, et al., "Interactive design and advanced manufacturing of double solar panel deployment mechanism for CubeSat, part 1: electronics design," Int J Interact Des Manuf, 2020. doi.org: 10.1007/s12008-020-00642-3.

[16] M. Ghodbane, et al., "Developpement d'un programme informatique pour la simulation du rayonnement solaire recu par une surface inclinee," Journée d'étude sur les énergies renouvelables et leurs applications, Université d'El Oued, 2015.

[17] J.-L. Bouvier, "Experimental study of a solar micro-cogeneration installation coupling a cylindro-parabolic concentrator and a Hirn cycle motor (In French)," Ph.D. Dissertation, Universite de LaRochelle, 2014.

[18] M. Doraghinejad and H. Nezamabadi-pour, "Black Hole: A New Operator for Gravitational Searchalgorithm," International Journal of Computational Intelligence Systems, vol. 7, no. 5, pp. 809-826.

[19] M. Amoozegar and E. Rashedi, "Parameter tuning of GSA using doe," in Computer and Knowledge Engineering (ICCKE), 2014 4th International eConferenceon, pp. 431-436, 2014.

[20] H. Chen, S. Li, and Z. Tang, "Hybrid gravitational search algorithm with random-key encoding scheme combined with simulated annealing," IJCSNS, vol. 11, pp. 6, 208, 2011.

[21] J. C. Bansal, S. K. Joshi, and A. K. Nagar, "Fitness varying gravitational constant in GSA," Applied Intelligence, pp. 1-16, 2018.

[22] S. Duman, et al., "Optimal power flow using gravitational search algorithm," Energy Conversion and Management, vol. 59, pp. 86-95, 2012.

[23] A. Bahrololoum, et al., "A prototype classifier based on gravitational search algorithm," Applied Soft Computing, vol. 12, no. 2, pp. 819-825, 2012.

[24] M. Khajehzadeh, et al., "A modified gravitational search algorithm for slope stability analysis," Engineering Applications of Artificial Intelligence, vol. 25, no. 8, pp. 1589-1597, 2012.

[25] A. Krothapalli and B. Greska, "Concentrated solar thermal power," Handbook of Climate Change Mitigation and Adaptation, pp. 1-27, 2014. 
[26] P. N. Patil, M. Khandekar, and S. N. Patil, "Automatic dual-axis solar tracking system for parabolic dish," in Advances in Electrical, Electronics, Information, Communication and Bio-Informatics (AEEICB), 2016 2nd International Conference on. IEEE, pp. 699-703, 2016.

[27] S. Racharla and K. Rajan, "Solar tracking system-a review," International Journal of Sustainable Engineering, vol. 10, no. 2, pp. 72-81, 2017.

[28] P. D. Medina, et al., "Thermal Energy Generation from A Solar Collector Parabolic Dish Reflector," International Journal of Renewable Energy Research (IJRER), vol. 9, no. 3, pp. 1500-1509, 2019.

[29] J. B. Lasich, "Solar tracking system," U. S. Patent 7,109,461, Sep. 192006.

[30] A. R. Nadia, et al., "Advances in solar photovoltaic tracking systems: A review," Renewable and sustainable energy reviews, vol. 82, pp. 2548-2569, 2018.

[31] W. Nsengiyumva, et al., "Recent advancements and challenges in Solar Tracking Systems (STS): A review," Renewable and Sustainable Energy Reviews, vol. 81, pp. 250-279, 2018. 